\title{
Information System Framework for Training Teachers on Computational Thinking
}

\author{
Ung Ling-Ling ${ }^{1}$, Jane Labadin ${ }^{2}$, Fitri Suraya Mohamad ${ }^{2}$ \\ ${ }^{1}$ Universiti Teknologi MARA (UiTM) Cawangan Sabah Kampus Kota Kinabalu, Beg Berkunci 71, \\ 88997 Kota Kinabalu, Sabah, Malaysia \\ ${ }^{2}$ Institute of Social Informatics and Technological Innovations, Universiti Malaysia Sarawak, \\ Kota Samarahan - Sarawak, Malaysia
}

\begin{abstract}
The call for a holistic integration of computational thinking (CT) skills across all subjects in the newly revised Malaysian curriculum of 2017 has brought to attention an urgent need to prepare teachers with the new syllabus, teaching and learning (TL) tools, and techniques, to promote effective computational thinking knowledge dissemination in their daily classroom practices. However, a preliminary investigation revealed that many teachers were still unaware of the changes within the new curriculum. There was an apparent lack of understanding of computational thinking skills in general. The study intends to propose a conceptual framework to develop knowledge about computational thinking skills among Malaysian teachers, to enhance their pedagogical repertoire to include elements of computational thinking into their teaching content. The study employs mixed-method research to capture data and construct interventions. The Information Systems Design Theory (ISDT) is used to design an effective information system (IS) and set a plan for developing the conceptual framework.
\end{abstract}

DOI: $10.18421 /$ SAR43-04

https://doi.org/10.18421/SAR43-04

Corresponding author: Ling-Ling Ung,

Universiti Teknologi MARA (UITM) Cawangan Sabah

Kampus Kota Kinabalu, Beg Berkunci 71,88997 Kota

Kinabalu, Sabah, Malaysia.

Email: ungli720@uitm.edu.my

Received: 15 June 2021.

Revised: 04 September 2021.

Accepted: 10 September 2021.

Published: 23 September 2021.

(c) (i) (c) 2021 Ung Ling-Ling, Jane Labadin \& Fitri Suraya Mohamad; published by UIKTEN. This work is licensed under the CC BY-NC 4.0.

The article is published with Open Access at www.sarjournal.com
The proposed framework comprises five elements, which could serve as a guide for future planning in setting up CT training for Malaysian teachers and other related professional development programmes.

Keywords - computational thinking, information system (IS), E-learning, teacher, Information System Design Theory (ISDT).

\section{Introduction}

Computational thinking (CT) is a fundamental skill for 21st-century learning [1], perhaps even in the 22nd century. CT skill is essential, capable of producing graduates equipped with critical skills for futuristic careers. As a result, many countries are incorporating CT concepts into their educational curriculum. Malaysia joins the bandwagon, as it claimed to be the first country in ASEAN to pioneer in the use of CT into its national education system; Malaysia does not only introduce CT for programming or computing based subjects, but its elements are incorporated into all subjects, including literature, art and health. Implementing newly integrated curriculum reflects the need to equip Malaysian educators sufficiently with CT knowledge, to enable a smooth integration and interpretation of CT into content knowledge.

Since 2016, professional development programs have been conducted to understand the CT definition among teachers. However, in a small cross-sectional study [2], findings indicated that most teachers were unaware of the inclusion of CT skills in the revised curriculum for 2017, resulting in the absence of using CT elements in their instructional delivery. The teachers who participated in the study also indicated a lack of understanding of $\mathrm{CT}$. The results sent alarming consequences, as they depicted an actual scenario in the classrooms. Without expertise and sufficient knowledge, teachers would not have been able to integrate CT skills into the subject contents they teach. Stemming for the concern, the study aims to investigate the viability of designing an Information System (IS), which would aid teachers to gain understanding and acquire mastery in integrating CT in their respective classrooms. 


\section{Background of the Study}

The Ministry of Education works closely with Malaysia Digital Economic Development (MDEC) to design and organize professional development programs to educate in-service and pre-service teachers to use and integrate $\mathrm{CT}$ elements into their teaching subjects. The CT training programs have started even before 2017; a strategy straddled to prepare the teachers to deliver the content of the newly revised curriculum. Several higher education institutions were selected and offered to assist with the training. Training modules were curated to guide teachers to build on their professional developments. Modules were constructed based on existing standards and benchmarks such as those by The International Society for Technology in Education (ISTE), programming using Scratch, and Google for Education: Computational Thinking.

However, the effectiveness of these training programs is questionable. Ung's survey in [2] found that $80 \%$ of its respondents indicated that they had not attended any formal training on CT. Despite all these, the training programs were unable to outreach a broad teacher's participation. $79.2 \%$ of the respondents declared they did not have a clear idea of what CT entails. A majority of the respondents also affirmed that they have misconceptions about the newly revised curriculum, as most thought of $\mathrm{CT}$ as a subject that dealt with only coding, an affinity toward computing in general. The study pointed toward the need to offer a better CT development system accessible to all teachers. The system has to be positioned as simple to access and relevant to the current needs of teachers to guide them in integrating $\mathrm{CT}$ into their lessons.

The nature of theory in IS can be categorised into five [3]: analyzing and describing the theory, understanding theory, predicting theory, explaining and predicting theory, and lastly, design and action theory. Information System Design Theory (ISDT) is categorised under the design and action theory, and it focuses on efficient design, implementation, use, and effects of information technology in organisations and communities. It emphasises how to design, generate principles, methods, and evaluate the outcome of the proposed solution. The guidelines for development increase reliability and the likelihood of success, leading to empirical testing and thus can form a basis for further research [4].

\section{Materials and Methods}

Using a mixed-method approach, the study uses the constructivist education paradigm to inform the structure and direction of the investigation. The mixed-method was chosen to identify social development problems and seek a fitting solution, and it is suitable for related educational practices. With Malaysia's newly revised curriculum, which entails integrating $\mathrm{CT}$, the methodology was apt to understand teachers' needs in dealing with a new set of knowledge for their instructional practice. The following diagram illustrates the flow of processes in the study. The paper describes the formulation of a conceptual framework that informs the design of an IS, which is recommended to train teachers on CT skills.

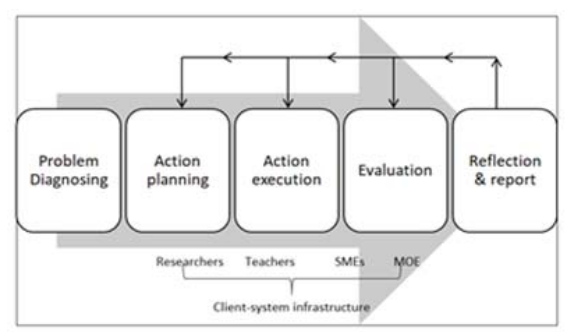

Figure 1. A holistic view of all research processes planned for the investigation

A working team is formed to ensure collective input, participation and collaboration from the researchers and the stakeholders (CT SMEs, MOE and the teachers). In the first instance, a simple preliminary investigation was carried out to diagnose a problem. School teachers participated in the initial study. Based on the preliminary investigation, the problem area was identified. Action planning began by asking questions such as: Do you have control over the problem? What is the goal of the solution? Is there any way to measure the solution? The literature review was conducted, which involved searching for published literature and government documents related to Malaysia's newly revised curriculum 2017, including CT training modules. To align what was found in previous research, a series of focused interviews was conducted with SMEs to gauge issues they face on the ground. A timeframe was set to execute the proposed intervention. These processes guided the problem focus, theoretical framework, and the framing of the proposed intervention.

\subsection{IS Model Formulation}

The first round of investigations led to the design of an IS. Its functions and values are constructed to meet the needs identified in the results from the initial study. Based on the initial investigation, the framework is proposed and grounded based on the following:

- A typical IS research would yield the needs of the end-user (actor) of services and products. Theoretically, different actors would have different preferences in using or attaching to specific digital devices [5]. Their study looked at 
actors' digital devices ownership and usage. Such focus on human behaviour is essential to plan for a secure yet efficient method to deliver CT knowledge via suitable digital devices, even when there are no digital means. Based on the actors identified for the present study, learning requirements were determined. The actors' role is to learn and understand the concept of CT so that they will be able to carry out the TL of CT in their daily instructional activities. The design of an IS that presents CT knowledge shall be built as an open system, with learning materials available to all users. It should not confine or constrain any teacher to his/her institutional level or university level.

- The interviews with SMEs suggested the learning experience first base to begin the learning experience must be based on the newly revised curriculum. A curriculum is typically defined as a set of guidelines for all-round educational growth that improves a learner's social, physical, emotional, and intellectual aspects. Without a curriculum, the objectives of learning cannot be achieved [6]. It is the mediator that communicates what teachers and learners should know and do. For curriculum changes and expected learning outcomes to be implemented, ongoing teacher's development has to be central to curriculum policy.

- Resulting from the interviews also suggested that E-learning can support learning features within the IS. It provides a platform for personalised learning. Types of support can vary depending on the needs of the learners; to tailor to the individual needs, skills, and interests of each learner. According to [7], there are seven critical dimensions in personalised learning, and they apply to the current study in that the target group for the IS needs a set of tasks and environments to encourage the learning of new knowledge and skills.

- In education, the system users refer to a group of learners who, through different learning experiences, learn skills or abilities. Teachers' learning environments are influenced by various factors, including institutional opportunities for professional development, the demands of specific teaching environments, the materials and human resources available to them, educational reform efforts, and policy directives from their schools and states [8]. Hence, in the interest of the current study, CT materials need to be designed, structured and executed where learners get prompted to apply the content to realclassroom situations. A teacher's understanding of the CT concept should not be limited to just one subject or discipline only. It should be treated as an essential skill, a process of thought in problem-solving [9]. The proposed framework aims to provide a CT concept description to dispel the misunderstanding and provide a comprehensive understanding of CT concepts linked to the real world and daily TL practices. It uses non-subject specific CT definitions and the provision of the existing TL plan associated with the CT concept. The CT concept, projection of pedagogies, and material featured on this IS will not be a constraint to a subject or based on computing discipline only.

- E-learning was decided because it offers a learning platform that is running 24/7. Nevertheless, educators and students are physically segregated in their own time, in which the two entities conduct separate TL processes at different locations. The use of E-learning in learning has resulted in delayed responses of educators in learning and technical issues. Inquiries from learners cannot be resolved immediately. SMEs have emphasised, while researches have proven that learner support, in the forms of technical or non-technical, played a crucial role in an IS success. Failure to address this support will be detrimental to the learning process, in which learners will experience learning difficulties, dissatisfaction, absenteeism, isolation, eventually resulting in learning withdrawal. The lack of learner support is a barrier to active online learning, which may eventually make the distance learner even more distant [10]. Therefore, adequate learning support is necessary to enhance the system's reliability and build student confidence in the projected IS. The support provision has to be in technical as well as learning aspects.

Permission was sought from the Ministry of Education, the gatekeeper for all education-related research, to test the intervention. An empirical experiment was conducted with the target group. Teachers from the Sabah region were invited to participate in the test. The teachers teach different subjects in various schools: rural area schools, schools in the urban, national schools, Chinese national type schools and as well as private schools. Pre-tests and post-tests were carried out to measure the impact of the suggested intervention. A final evaluation exercise was done at the end of the intervention to measure the acquisition of $\mathrm{CT}$ knowledge indicated in the study.

\subsection{IS Efficacy Constructs}

The study intends to propose an IS to guide teachers to learn about CT. However, how do we measure the success of the intervention? What are the learning impacts on the target users? What elements have to be in place to ensure learning happens efficiently? Previous literature has described benefits from various perspectives, 
improving user's productivity, quality of life and social life, making work more comfortable and more enjoyable, or measured based on operational, technological and economic effectiveness. The Information System Success (ISS) model [11] comprises:

- System quality measures the information system processing itself; correspond to the technological, performance, and usability characteristic.

- Information quality corresponds to the system's accuracy, validity, and currency regarding the system contents.

- Service quality refers to the quality of service that the system can provide, assessed based on the responsiveness and perceived competence of the technical staff.

- The IS use is determined by the quality of the information, system, and service, user satisfaction tests the degree of user satisfaction, including overall interface satisfaction; and lastly,

- The perceived individual and organisational effect on tasks/job performance and productivity are net benefits.

To date, many studies have the ISS model in evaluating the success of the IS project, especially from the perspective of E-learning [12]. The mentioned research concluded that information quality, service quality, and system quality directly impact E-learning systems use and satisfaction. Based on those as mentioned above, it is decided that this IS proposal incorporates E-learning. This decision was made because E-learning can provide the benefits as follows:

- Malaysia consists of thirteen states and one federal territory. Teachers are assigned to teach across the country, from urban to the most remote parts of Malaysia. With E-learning, teachers can attend professional development programmes without having to travel to specific training locations. Teachers can learn at their locations in their own time. E-learning has enabled teachers to saves time and cost [12].

- It provides broader scalability and a quicker approach to learning. It provides a platform for more extensive participation of teachers;

- The learning materials are made available 24/7, enabling training to be followed at different timeframes and without exhausting physical resources that are typically needed to make a training programme happen;

- Without a fixed class or training timetable, teachers can manage their work and family life [13];

- It provides shared space to support collaboration and support from more advanced learners [12], encouraging learning, especially among adult learners.
Figure 2 depicts how the ISDT model is mapped onto the teacher training module.

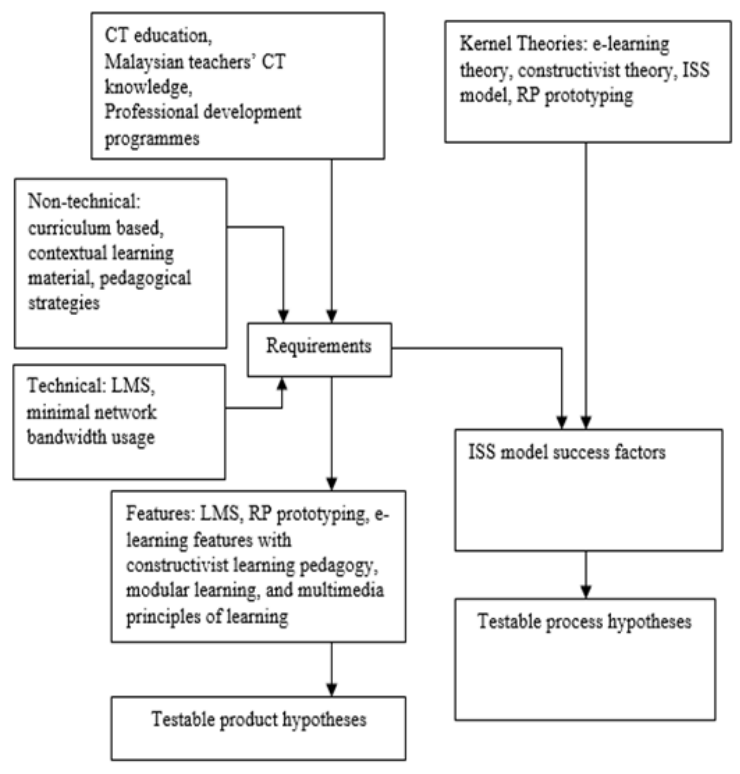

Figure 2. Components of the proposed action mapped with the ISDT model

\section{Results and Discussions}

A framework to impart CT knowledge to Malaysian teachers is proposed, which comprises five elements: learning requirements, technology, learning support, contextual learning, and lastly, effective learning strategies.

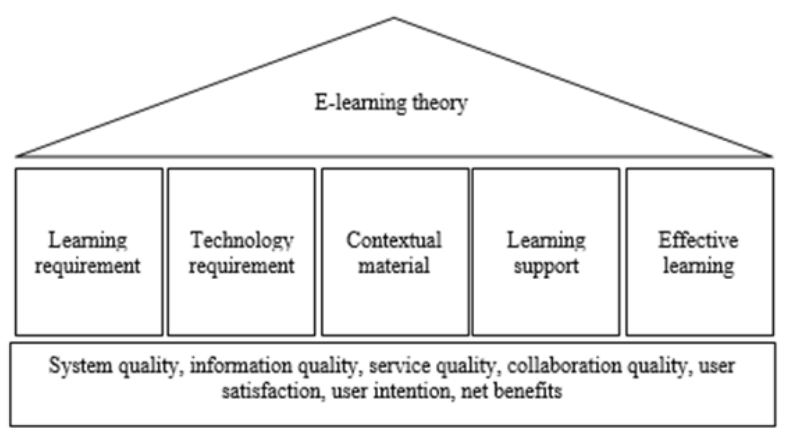

Figure 3. The proposed IS framework for training teachers on Computational Thinking

The ISDT for E-learning proposed in the study is grounded on the [3] model, which comprises kernel theories, requirements, features, development practices, design principles, and testable hypotheses. The kernel theories of the ISDT for this research are driven by the constructivist theory, previous works on E-learning. These elements are decided based on preliminary review and data analysis carried out, associated the research issues with information containment and generation and E-learning associated with a community learning outside an education institution. 


\subsection{Learning Requirements}

The first construct of the framework, the learning requirement, addresses $\mathrm{CT}$ content based on the national curriculum, using existing TL knowledge, practices and affordable technology. Apart from these, the teacher's prior content and technological knowledge and experience are considered during the construction of the E-learning system.

\subsection{Technology Requirements}

This E-learning development needs to be implemented and completed immediately; hence an existing Learning Management System (LMS) is employed. The use of existing LMSs shortens the time required for the development. The selected LMS is open-source, and most importantly, it is free. It provides hypermedia features that are easy to use, flexible, and compatible with standard browsers and mobile phones [14]. The use of an existing hypermedia template is proposed and encouraged by many as it offers an approach to documenting and supporting the reuse of design [3].

\subsection{Effective Learning}

The goal of this E-learning system is to focus more on knowledge generation by the teachers instead of knowledge acquisition. It is achieved by incorporating different practical learning approaches such as:

- Learning content will be segmented into small modules to avoid excessive information at a time [15].

- Reflection, inquiry-based instruction, and sensemaking learning improve CT classroom practices and eventually creating relevant domain-related solutions [16]. Instead of merely memorising and remembering rules, concepts, or formulas, their curiosity and basic knowledge help them engage and develop a deeper understanding of CT topics and content.

- Collaboration learning to build social or community networks encourages teachers to create their own CT knowledge repository (materials, technologies, and contents) through sharing, disseminating, and exchanging TL practices or information. It can improve their CT TL knowledge and approaches.

- Self-regulated learning puts the responsibilities of learning on the teacher (the learner). The teacher takes charge of his or her learning. They self-managed the learning pace, accessing to the choice of learning content to develop skills [16]. Furthermore, self-regulated learning is one of the most mentioned predictors of learner's satisfaction.

- Personalised learning creates a more engaging and dynamic learning environment by tailoring to individual learners' interests, needs, and skills. It allows the educator to bring more robust, practical, and varied material into the learning space [17].

- The multimedia learning principle is included, too. In a multimedia learning environment, images, video and animations alongside texts stimulate the brain, improving learners' attention and information retention [18].

\subsection{Contextual Learning}

The proposed framework focuses on providing a CT concept description to dispel the misunderstanding and a comprehensive understanding of $\mathrm{CT}$ concepts linked to the real world. It will be carried out by using non-subject specific CT definitions. The CT concept, projection of pedagogies, and material featured on this website will not be a constraint to a subject or based on computing discipline only. Pedagogies and technologies proposed in the E-learning will not be new to the teachers but adaptable to their daily TL of CT. It will emphasise the existing pedagogy and existing technologies to carry out $\mathrm{TL}$ of $\mathrm{CT}$, providing comprehensible CT learning to the teachers. [19] emphatically stated that a curriculum framework conceptualised in a generic form would allow teachers the freedom and agency to adapt and customise the framework as they see fit for their classrooms and students. It offers teachers the freedom to implement the new curriculum based on their existing pedagogies and technologies knowledge, depending on the student needs. Examples of TL resources will be provided based on the Malaysian curriculum climate.

\subsection{Learning Support}

Finally, under learning support, the system shall provide a means of communication to connect to facilitators for learning or technical assistance and exchange learning outcomes or opinions with other teachers (the learners). Learners build an academic rapport that facilitates knowledge containment, ensuring better learning outcomes and the enjoyment of the learning process [20].

The initial proposed model includes five independent constructs: learning requirements, effective learning, learning support, technology, and contextualised learning. Table 1 depicted each construct and the descriptions. 
Table 1. Framework constructs descriptions

\begin{tabular}{|l|l|}
\hline \multicolumn{1}{|c|}{ Constructs } & \\
\hline \multirow{4}{*}{ Learning requirements } & Based on the national curriculum goal \\
\cline { 2 - 2 } & Pedagogy requirements \\
\cline { 2 - 2 } & Technological requirements \\
\hline \multirow{4}{*}{$\begin{array}{l}\text { Contextualised learning } \\
\text { material }\end{array}$} & Provides interactivity \\
\cline { 2 - 2 } & Provides non-linear learning \\
\hline \multirow{5}{*}{ Effective learning } & $\begin{array}{l}\text { PT concept as problem-solving skills } \\
\text { knowisions of learning material using existing classroom pedagogies and technologies }\end{array}$ \\
\hline \multirow{5}{*}{ Learning support } & Knowledge generation \\
\cline { 2 - 2 } & Modular learning \\
\cline { 2 - 2 } & Collaborative-learning \\
\cline { 2 - 2 } & Personalised learning \\
\cline { 2 - 2 } & Inquiry-based learning \\
\cline { 2 - 2 } & Multimedia-based learning \\
\cline { 2 - 2 } & Self-regulated learning \\
\hline & Provision of a means of communication to connect to facilitators \\
\cline { 2 - 2 } & Provision of an academic rapport among learners \\
\cline { 2 - 2 } & Provides automated feedback features \\
\cline { 2 - 2 } & Provides a platform to seek technical support \\
\hline
\end{tabular}

The present study proposes a possible hypothesis for empirical testing. Information System Success model (ISS) by [11] and [21] are adopted to measure the effectiveness and success factors delivered by the proposed E-learning in providing $\mathrm{CT}$ knowledge to the Malaysian teachers. [21] collaborative construct measures the success level of teacher's exchanging information as well as collaboration between them.

System quality by [11] is an essential determinant of the quality of the proposed E-learning. It corresponds to the technological characteristics: system availability, ease of use [22], network performance, effective learning and usability of the system. [23] stressed that if the IS is simple and easy to use, an individual will feel that the IS is beneficial and will be more likely to use E-learning technology for learning. The literature shows that system performance on technology, especially network conditions, significantly affects the infusion or adoption of new IS innovations [24].

By its focus on learning, the proposed E-learning focuses on learning effectiveness. E-learning with technology integration with relevant pedagogy influences learners' intention and satisfaction and infuses better learning outcomes. Quizzes, games, discussion rooms, question and answers activities are examples of crucial E-learning features in enhancing TL processes. The significant relationship between system quality and both use and satisfaction with the LMS was found in many studies [14], indicating the importance of effective TL usability design. This construct is even more significant in the E-learning system because of the compulsory use in TL activities. The hypotheses are, therefore, articulated as follows:
H1. System quality will positively affect user's intention in using the proposed E-learning.

H2. System quality will positively affect usersatisfaction.

Information quality refers to the information generated by the proposed IS. It is an essential requirement for E-learning. The information generated has to be relevant to the content subject, reliable, and accurately reflect current knowledge. The IS system work by [12], [24] attributes such as accuracy, precision, currency, reliability, completeness, conciseness, relevance, understandability, timeliness, and format. In the Elearning system, the quality of information plays a vital role in ensuring the success of the learning. Students procure learning from E-learning; thus, the information provided has to be of high quality to warrant that the learning goals are met. [25] investigation has proven the significant influence of information quality on user acceptance towards an IS. For example, [13] stated that quality information that is appropriate and sufficient, precise, up-to-date, and comes with attractive web design contributes to the learner's overall learning satisfaction. Therefore, this research assumes that improved quality of the information in the E-learning system will positively lead to an increase in user intention and user satisfaction:

H3. Information quality will positively affect user intention in using the proposed E-learning.

H4. Information quality will positively affect user satisfaction. 
Service quality is added into the revised D\&M IS success model [11] as an antecedent of use and user satisfaction. The construct refers to the overall support delivered by the proposed IS provider. Despite the sophisticated technology and evolution, it is useless if technical and learning support services do not meet IS user expectations. Research results have shown that the intended use and satisfaction of an IS is highly influenced by service quality [13]. Efficient service support can be measured by support responsiveness, empathy, trust, and perceived competence of the technical staff or facilitator [25]. Guidance and technical support are essential to facilitate learners' engagement. When a learner lacks sufficient skill to operate the IS, or even facing learning hiccups, the supporting conditions, such as technical instruction, learner's guidance, and personal assistance, are rendered important [26]. Hence, hypotheses are made as follows:

H5. Service quality will positively affect user intention in using the proposed E-learning.

H6. Service quality will positively affect user satisfaction.

Collaboration features in E-learning allow learners to work and collaborate to learn and grow with each other. Interaction between learner-to-learner and learner-to-educator play a crucial part in making TL of an E-learning a success due to the isolation of educators and learners [27]. Collaboration refers to a discussion, arguments, and conversation activities that take place in the learning process. It can develop higher-level thinking skills and boost their confidence and self-esteem as well [12]. It creates a better meaningful learning experience which positively impacts learning outcomes and allowing learners to explore new territory. Collaborative features are also a catalyst for knowledge building. Additionally, [28] stated that in any IS, knowledge sharing and exchanging is a significant component. Hence this approach is appropriate in this study given that the concept of CT is a relatively new field in the Malaysian education system. Collaborative quality [21] is based on digital communication technology available from mobile phones and computers; stressed that the quality of the collaboration has to be carefully considered and addressed when aiming for a successful IS deployment Some of its features are e-mail, blogging, discussion forums, alert functions and texting. Since then, many have imparted it as an essential feature in IS, especially in E-learning. Collaboration quality is measured based on ease of use, efficiency, and comfortability [12], [27] supporting communications and knowledge sharing. Therefore, the current research hypothesises that:

H7. Collaboration quality will positively affect user intention in using the proposed E-learning.
H8. Collaboration quality will positively affect user satisfaction.

User satisfaction does mediate the intention to continue or even recommend others to the newly proposed IS, and contented learners led to loyalty, just as satisfied customers continue to use the same brand [10]. The influence of user satisfaction towards intention to use the proposed IS is frequently discussed in E-learning system deployment [29]. The more students are satisfied with the learning, the more they will continue to use E-learning. Hence, hypothesis:

H9. User satisfaction will positively affect user intention.

According to [30], user satisfaction with the proposed learning IS is also consistently associated with learning outcomes. If the learners are pleased with the IS intervention, that means that the benefits of E-learning have been successfully channelled. Thus, user satisfaction is grasped as a positive, indifferent, or hostile feeling [13]. User satisfaction measures the successful interaction between an IS and its users [29]. In this case, the learning content to its learners. Many empirical studies have shown that user satisfaction is a critical component in determining the success and sustainability of an IS, especially the E-learning system. Accordingly, the hypothesis is put forward as follows:

H10. User satisfaction will positively affect Elearning net benefits.

System usage construct can also be operationalised as the possibility to use and intention to use [24]. It refers to is the indication if a user intended to continue utilising the proposed IS. Learners will continue to use the proposed IS if they find Elearning beneficial and vice versa [11]. Several studies [31] underpin this relationship between user intention and the success of an IS. In this study, it is expected that learners perceive IS contribution to the improvement of their CT TL performance in the classroom. Hence, hypotheses are as follows:

H11. User intention will positively affect Elearning net benefits.

Figure 4 illustrated measurable hypotheses in Elearning.

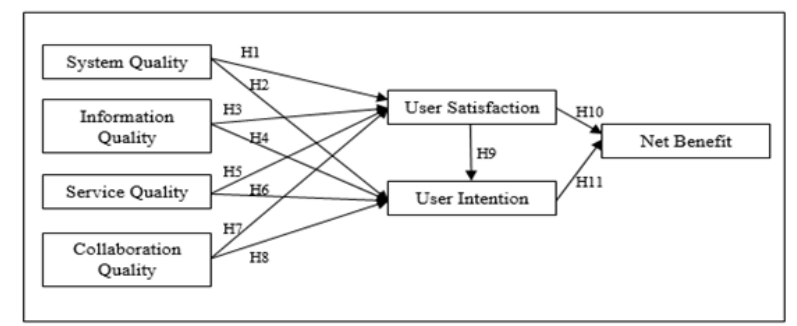

Figure 4. E-learning measurable hypotheses 


\section{Conclusions}

The study is motivated by the Malaysian newly revised curriculum of 2017 . The changes have affected national education practices, placing a need for improvements in many aspects. Based on a pilot study by [2], a professional development system to impart CT knowledge to all Malaysian teachers is required. In the study, the ISDT model [4] is referred to design and develop an IS system via E-learning to disseminate CT concept knowledge to Malaysian teachers. The research process model can guide researchers working on CT-based education research, find information or literature related to the CT concept based on Malaysia TL classrooms, and serve as a practical guideline for future research.

The research was initiated with several theorybased principles that are subject to empirical validation. The ISDT manages to produce an Elearning that applies to a non-institutional environment (outside any school and university). The ISDT provision a flexible E-learning system, free and accessible to all teachers. The most significant feature of the E-learning system is the establishment of contextual learning material, supported by constructivist learning theory. The approach will help build contextual content; in the future will benefit the Malaysian CT education system. This research is formulated based on empirical findings (will be reported in the future) and through the kernel theories derived from relevant literature, design requirements, and testable hypotheses. A framework to impart CT knowledge to Malaysian teachers is proposed, which comprises five elements: learning requirements, technology, learning support, contextual learning, and lastly, effective learning strategies. The final framework in Figure 3 includes E-learning interventions and success measurements that can be utilized, integrated, and combined to provide professional development of the CT concept for Malaysian teachers. An empirical investigation of the proposed E-learning is still in progress. The Elearning system is tested with a group of teachers in Malaysia. This part of the work will provide the success factors in delivering CT knowledge to the teachers.

\section{References}

[1]. Wing, J. M. (2006). Computational thinking. Communications of the ACM, 49(3), 33-35.

[2]. Ling, U. L., Saibin, T. C., Labadin, J., \& Aziz, N. A. (2017). Preliminary investigation: Teachers' perception on computational thinking concepts. Journal of Telecommunication, Electronic and Computer Engineering (JTEC), 9(2-9), 23-29.

[3]. Jones, D., Gregor, S., \& Lynch, T. (2003, June). An information systems design theory for web-based education. In IASTED International Symposium on Web-based Education (pp. 1-6).

[4]. Jones, D., \& Gregor, S. (2006). The formulation of an information systems design theory for e-Learning. In First International Conference on Design Science Research in Information Systems and Technology, Claremont, $C A$ (pp. 356-373).

[5]. Demetis, D., \& Lee, A. S. (2018). When humans using the IT artifact becomes IT using the human artifact. Journal of the Association for Information Systems, 19(10), 5.

[6]. Misfeldt, M., Tamborg, A. L., Dreyøe, J., \& Allsopp, B. B. (2019). Tools, rules and teachers: The relationship between curriculum standards and resource systems when teaching mathematics. International Journal of Educational Research, 94, 122-133.

doi: 10.1016/j.ijer.2018.12.001.

[7]. Organisation for Economic Co-operation and Development \& Centre for Educational Research and Innovation. (2007). Personalising education, OECD, Paris. http://hdl.voced.edu.au/10707/143029.

[8]. Council, T. A., \& National Academies of Sciences, Engineering, and Medicine. (2016). Science teachers' learning: Enhancing opportunities, creating supportive contexts. National Academies Press.

[9]. Mohaghegh, M. \& McCauley, M. (2016). Computational thinking: The skill set of the $21 \mathrm{st}$ century. International Journal of Computer Science and Information Technologies (IJCSIT), 7(3), 15241530 .

[10]. Huong, V. T., Casadesus, M., \& Marimon, F. (2017). Assessing learner satisfaction by simultaneously measuring learner attitude, motivation, loyalty and service quality in English academies. Innovations in Education and Teaching International, 54(4), 301312. doi: 10.1080/14703297.2015.1088397.

[11]. DeLone, W. H., \& McLean, E. R. (2003). The DeLone and McLean model of information systems success: a ten-year update. Journal of management information systems, 19(4), 9-30. doi: 10.1080/07421222.2003.11045748

[12]. Cidral, W. A., Oliveira, T., Di Felice, M., \& Aparicio, M. (2018). E-learning success determinants: Brazilian empirical study. Computers \& Education, 122, 273-290. doi: 10.1016/j.compedu.2017.12.001

[13]. Al-Fraihat, D., Joy, M., \& Sinclair, J. (2020). Evaluating E-learning systems success: An empirical study. Computers in human behavior, 102, 67-86. doi: $10.1016 /$ j.chb.2019.08.004. 
[14]. Ouadoud, M., Chkouri, M. Y., \& Nejjari, A. (2018). Learning Management System and the Underlying Learning Theories: Towards a new Modeling of an LMS. International Journal of Information Science and Technology, 2(1), 25-33.

[15]. Jagušt, T., \& Botički, I. (2019). Mobile learning system for enabling collaborative and adaptive pedagogies with modular digital learning contents. Journal of Computers in Education, 6(3), 335-362.

[16]. Ranieri, M., Raffaghelli, J., \& Pezzati, F. (2018). Building cases for faculty development in e-learning: a design-based approach.Form@ re-Open Journal per la formazione in rete, 18(1), 67-82.

[17]. Aziz, N. A., Eassa, F., \& Hamed, E. (2019). Personalized learning style for adaptive e-learning system. International Journal of Advanced Trends in Computer Science and Engineering, 8(1), 223-230.

[18]. Mayer, R. E. (2017). Using multimedia for elearning. Journal of Computer Assisted Learning, 33(5), 403-423.

[19]. Angeli, C., Voogt, J., Fluck, A., Webb, M., Cox, M., Malyn-Smith, J., \& Zagami, J. (2016). A K-6 computational thinking curriculum framework: Implications for teacher knowledge. Journal of Educational Technology \& Society, 19(3), 47-57.

[20]. Al-Emran, M., \& Teo, T. (2020). Do knowledge acquisition and knowledge sharing really affect elearning adoption? An empirical study. Education and Information Technologies, 25(3), 1983-1998.

[21]. Urbach, N., \& Müller, B. (2012). The updated DeLone and McLean model of information systems success. In Information systems theory (pp. 1-18). Springer, New York, NY.

[22]. Martins, J., Branco, F., Gonçalves, R., Au-YongOliveira, M., Oliveira, T., Naranjo-Zolotov, M., \& Cruz-Jesus, F. (2019). Assessing the success behind the use of education management information systems in higher education. Telematics and Informatics, 38, 182-193. doi: 10.1016/j.tele.2018.10.001

[23]. Elkaseh, A. M., Wong, K. W., \& Fung, C. C. (2016). Perceived ease of use and perceived usefulness of social media for e-learning in Libyan higher education: A structural equation modeling analysis. International Journal of Information and Education Technology, 6(3), 192. doi: 10.7763/IJIET.2016.V6.683
[24]. Kurt, Ö. E. (2019). Examining an e-learning system through the lens of the information systems success model: Empirical evidence from Italy. Education and Information Technologies, 24(2), 1173-1184. doi: 10.1007/s10639-018-9821-4.

[25]. Al-Samarraie, H., Teng, B. K., Alzahrani, A. I., \& Alalwan, N. (2018). E-learning continuance satisfaction in higher education: a unified perspective from instructors and students. Studies in higher education, 43(11), 2003-2019. doi: 10.1080/03075079.2017.1298088.

[26]. Smidt, E., Cheong, C. Y. M., \& Kochem, T. (2020). The meaning of quality in online/blended learning at a Malaysian university. International Journal on ELearning, 19(3), 243-263.

[27]. Lee, J., Song, H. D., \& Hong, A. J. (2019). Exploring factors, and indicators for measuring students' sustainable engagement in elearning. Sustainability, 11(4), 985.

[28]. Migdadi, M. M., Zaid, M. K. S. A., Al-Hujran, O. S., \& Aloudat, A. M. (2016). An empirical assessment of the antecedents of electronic-business implementation and the resulting organizational performance. Internet Research.

[29]. Tan, T. S., Chen, T. L., \& Yang, P. H. (2017). User satisfaction and loyalty in a public library setting. Social Behavior and Personality: an international journal, 45(5), 741-756.

doi: 10.2224/sbp.5999 Rossin, D., Ro, Y. K., Klein, B. D., \& Guo, Y. M. (2009). The Effects of Flow on Learning Outcomes in an Online Information Management Cou. Journal of information systems education, 20(1), 87-98.

[30]. Rossin, D., Ro, Y. K., Klein, B. D., \& Guo, Y. M. (2009). The Effects of Flow on Learning Outcomes in an Online Information Management Cou. Journal of information systems education, 20(1), 87-98.

[31]. Garg, S., \& Sharma, S. (2020). User satisfaction and continuance intention for using e-training: A structural equation model. Vision, 24(4), 441-451. 